\title{
Safe Passages
}

\section{Pro-Life Response to the Tragedy of Maternal Deaths}

\section{George Mulcaire-Jones, M.D., and Robert Scanlon, M.D.}

Dr. Mulcaire-Jones is president of Maternal Life International (MLI), starting its twelfth year as a global, non-profit AIDS avoidance and family health services organization based in Butte, Montana. He practices family medicine and obstetrics in Butte. He may be contacted at gmuljones@gmail.com.

Dr. Scanlon is MLI's director of medical programs. He also heads an MLI affiliate called Aiding Infants and Mothers (AIM), an organization based on Long Island, New York, that helps pay medical bills for needy, pregnant women in Africa and helps provide medicines, equipment, and supplies as part of the Safe Passages program. He is a practicing ob/gyn in Huntington, New York.

\begin{abstract}
Maternal mortality in Africa remains unacceptably high. The prevailing response to reducing maternal mortality has emphasized "reproductive health" and has failed to clearly focus on those causes responsible for 90 percent of maternal deaths. In contrast, the "Safe Passages" model directs training and resources toward interventions that save the lives of mothers and babies. Within the Safe Passages model, a "premise" and an "equation" offer an ethical and strategic framework for maternal health-care development which respects human life and dignity and prioritizes those interventions most likely to reduce maternal and newborn deaths. The Safe Passages "equation" emphasizes the key components of respect for
\end{abstract}

The Linacre Quarterly 78(2) (May 2011): 202-210.

(C) 2011 by the Catholic Medical Association. All rights reserved. 0024-3639/2011/7802-0010 \$.30/page. 
persons, safe birth, and fertility literacy. Successful training and development programs should work to insure participants and organizations are inspired, educated, equipped, and evaluated.

In a village hollowed out in the mangrove forests of Sierra Leone, a woman of eighteen struggles to give birth. She pushes from early in the day into the waning hours of the night. At first she bears the pain stoically. As the hours go on, she begins to cry out. When dawn breaks, she lies in sheer exhaustion. Blood begins to seep from her birth canal-a drop, a trickle, a steady stream. As the sun rises above the horizon she slips into a coma. The sky is streaked in purple, her garments are soaked blood red, her rich brown skin pales. All is quiet. Death holds neither light nor color; its darkness diminishes us all.

How can it be, this death of a woman in the very act of giving life? Her death leaves a void in her family and community that can never be filled. For more than twenty years, the United Nations has promised to address and resolve the tragedy of maternal deaths in the developing world, yet in vast sectors of Africa, little has changed. Women continue to die of complications, which have been effectively treated in the developed world for nearly one hundred years. The most recent estimates of maternal mortality indicate that the maternal death rate in Africa is still 640 per 100,000 live births, compared to a rate of 14 per 100,000 in developed countries. This is the widest known disparity in comparative public-health statistics. ${ }^{1}$

In 1987, the "Safe Motherhood Initiative" was launched in Nairobi, Kenya. ${ }^{2}$ Since that time, increasing attention and funding have been directed to reducing maternal deaths under the umbrella of "Safe Motherhood." Reducing maternal mortality by three-quarters by 2015 is one of the five United Nations millennium goals. ${ }^{3}$

While there is universal agreement on the need to reach this goal, the question of how to do so is not only elusive, but extraordinarily divisive. There remains a chasm between the villages of Africa and the cities of Geneva, Stockholm, London, and Washington, D.C. It is the chasm representing the distance between a woman dying in a birthing hut without sanitation, running water, or hope, and the carpeted board rooms where strategies are developed and priorities assigned. Vast resources, which should have been directed to funding improvements in essential obstetrical care, have gone to a different agenda-so called "reproductive health." Rather than focus on the real causes and solutions to maternal mortality, Safe Motherhood has become entangled within a "reproductive rights" agenda, which emphasizes access to contraception and promotes abortion.

In the middle of the night, a woman bleeding to death from a postpartum hemorrhage cannot be saved by a contraceptive device or a reproductive health mandate. An asphyxiated newborn cannot be resuscitated by the failed intent to prevent his or her conception. 
Data from the World Health Organization (WHO) demonstrate women in Africa die from five major causes: hypertensive diseases, obstructed labor, hemorrhage, sepsis and infection, and HIV-related diseases. ${ }^{4}$ While the exact prevalence varies from region to region (for example, Southern and Eastern Africa have higher HIV infection rates), the same complications are generally present (see table 1 ).

Tragically, the prevailing reproductive-health paradigm has not only ignored this data, it has betrayed the basic premise of obstetrical care: obstetrics is the care of two persons: a mother and her fetus. How is it that Safe Motherhood became invested primarily in preventing women from becoming pregnant, rather than caring for women who are expecting a baby and the baby itself? In the extreme, advocates for Safe Motherhood have been advocates of expansive medical and surgical abortion, ${ }^{5}$ regardless of its safety and the lack of facility-based care for post-abortion complications. In an Orwellian way, an abortion-driven agenda has become more important than the lives of African mothers:

In addition to the direct effects of induced abortion on women, there is the dangerous diversion of financial resources from interventions known to reduce maternal mortality: skilled birth attendants, antibiotics, blood banking, and uterotonics. Abortion, spontaneous and induced, accounts for less than 5 percent of maternal mortality. It is

Table 1 Causes and Percentages of Maternal Deaths in Africa*

\begin{tabular}{|c|c|c|c|c|}
\hline Cause of Death & $\begin{array}{c}\text { WHO } \\
\text { Analysis }\end{array}$ & $\begin{array}{l}\text { Ministry } \\
\text { of Health, } \\
\text { Uganda }\end{array}$ & $\begin{array}{c}\text { Nigeria } \\
\text { Federal } \\
\text { Ministry of } \\
\text { Health/WHO }\end{array}$ & $\begin{array}{l}\text { Department } \\
\text { of Health, } \\
\text { Republic of } \\
\text { South Africa }\end{array}$ \\
\hline Hemorrhage & $25 \%$ & $26 \%$ & $23 \%$ & $13.9 \%$ \\
\hline Infection/sepsis & $15 \%$ & $22 \%$ & $17 \%$ & $12.4 \%$ \\
\hline $\begin{array}{l}\text { Non-pregnancy-related } \\
\text { infections }\end{array}$ & & & & $31.4 \%$ \\
\hline Malaria & & & $11 \%$ & \\
\hline Obstructed labor & & $13 \%$ & $11 \%$ & \\
\hline $\begin{array}{l}\text { Pre-existing medical } \\
\text { conditions }\end{array}$ & & & & $7 \%$ \\
\hline Anemia & & & $11 \%$ & \\
\hline Hypertension/toxemia & $12 \%$ & $6 \%$ & $11 \%$ & $20.7 \%$ \\
\hline Abortion & $13 \%$ & $8 \%$ & $11 \%$ & \\
\hline $\begin{array}{l}\text { Other causes } \\
\text { (direct/indirect) }\end{array}$ & $28 \%$ & $25 \%$ & $5 \%$ & \\
\hline
\end{tabular}

* Data from Khalid S. Khan et al., "WHO Analysis of Causes of Death: A Systematic Review," Lancet 367 (2006): 1066-1074; and ministries of health of Uganda, Nigeria, and South Africa. 
scientifically, medically, and morally unacceptable to divert resources from interventions proven to reduce maternal mortality to the provision of abortion, under the guise of "decreasing unsafe abortion." The better way to reduce the human rights dimension of maternal mortality is to provide resources targeting the causes of 90 percent of maternal mortality. ${ }^{6}$

This "better way" to reduce maternal mortality lies in a different paradigm-a paradigm founded on respect for the life and dignity of the human person. In 2003, Maternal Life International was asked to assist the Catholic Secretariat of Nigeria (the organizational arm of the Nigerian Catholic Conference of Bishops) in developing a programmatic response to maternal mortality in Nigeria. Nigeria, particularly in the north, has one of the highest maternal death rates in Africa. The program we developed is called "Safe Passages." Safe Passages is predicated on a "premise" and an "equation" which formulate a strategic and ethical framework to improve maternal and newborn health care in Africa.

\section{The Safe Passages Premise}

Every mother and baby should be entitled to a safe passage: to a pregnancy and birth free of death, free of serious injury, and free of the HIV virus. The Safe Passage premise clearly states the goal of obstetrical care: to maximize the life, health, and well-being of a mother and her baby. Within this premise, we work to improve levels of basic and comprehensive emergency obstetrical care and to provide medications necessary to reduce mother-to-child HIV transmission. Within this premise, we work to prevent serious injury such as obstetrical fistula. The premise safeguards the sanctity of human life and prioritizes improvements in health-care delivery.

The Safe Passages premise is based upon accumulated historical and evidence-based data that clearly demonstrate when women and babies die in childbirth: from the onset of labor until seven days postpartum. ${ }^{7}$ We call this time frame the "window of vulnerability" (see figure 1). The window exposes the futility of antenatal care as a primary strategy in reducing maternal deaths-women generally do not die before going into labor. And the window further exposes the exaggeration of abortion-related deaths. If women were really dying in these kinds of numbers from so-called "unsafe abortions," would not the statistical numbers show a clear spike early in pregnancy? Exaggeration of abortion-related deaths is used to promote "safe," legal abortions.

What saves the lives of mothers and babies during this window of vulnerability is the presence of skilled birth attendants. A skilled birth attendant can recognize complications and initiate appropriate interventions. For example, they are able to:

- clinically and graphically monitor labor to recognize a woman who is developing obstructed labor; 


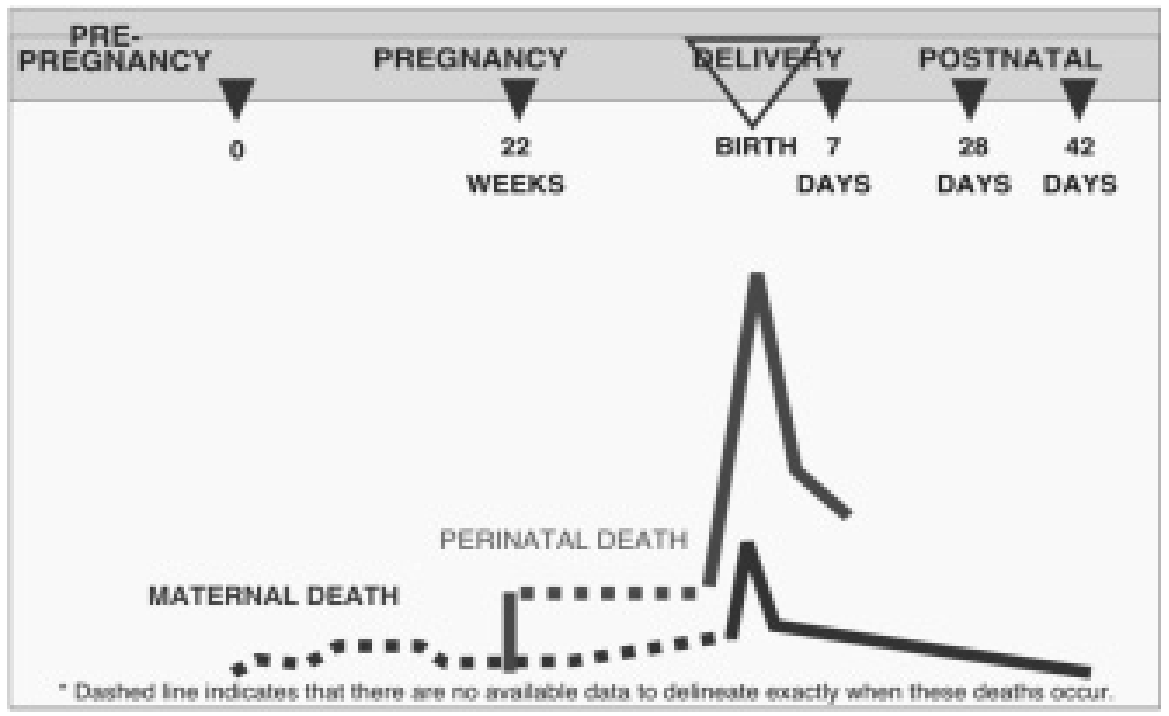

Figure 1 The Window of Vulnerability in the Timing of Maternal and Perinatal Deaths. Adapted from M. Koblinsky et al., "Issues in Programming for Safe Motherhood" (Arlington, VA: John Snow, Inc., MotherCare, September 2000), 8, http://pdf.usaid.gov/pdf_ docs/PNACK513.pdf. Used by permission of John Snow, Inc.

- recognize severe preeclampsia (toxemia) and administer magnesium sulfate and move the woman to delivery;

- actively manage the third stage of labor to reduce the incidence and severity of post-partum hemorrhage;

- intervene with uterotonic agents and intravenous fluids to treat a major post-partum hemorrhage;

- perform a Cesarean-section for obstructed labor;

- provide bag and mask resuscitation to an asphyxiated newborn;

- recognize and treat a septic newborn with appropriate antibiotics.

Safe Passages training also introduces safe anesthetic techniques and appropriate technical interventions such as the use of a vacuum extractor for a prolonged second stage.

\section{The Safe Passages Equation}

\section{Respect for Persons + Safe Birth + Fertility Literacy $=$} Healthy Mothers, Healthy Families, Healthy Nations

Like the Safe Passages premise, the Safe Passages equation focuses obstetrical care on what really saves the lives of mothers and babies:

- Respect of Persons: This component is at the heart of Catholic health care. Pope John Paul II stated, in Evangelium Vitae, "The 
first and foundational step in this cultural transformation consists in forming consciences with regard to the incomparable and inviolable worth of every human life." 8 The woman in labor is cared for as a gift rather than as a "problem" or a "burden." She is treated kindly, compassionately, warmly. No woman, regardless of her economic class, religion, or tribal affiliation is ever treated rudely or brusquely.

- Safe Birth: This component of the equation returns obstetrical care to its foundation: the quality care of a mother and her unborn or newborn baby. Safe birth targets the five conditions which lead to the vast majority of maternal deaths. Additionally, Safe Birth provides training for those conditions which lead to the majority of perinatal deaths: asphyxia, sepsis, birth trauma, and prematurity.

- Fertility Literacy: Fertility literacy refers to practical systems that teach couples natural means of family planning. With increasingly complex (and, in some countries, coercive) social and political structures, fertility literacy can be as critical to human development as written literacy. Unlike contraceptive technology, fertility literacy is a shared method which involves the active participation of both husband and wife. Fertility literacy empowers couples with knowledge and respect for their fertility and sexuality, fostering values and behaviors of chastity, self-control, spousal communication, and respect for women. An embrace of fertility literacy prevents the kinds of abuses which stem from population control, ranging from coerced sterilization in Indonesia and Peru to forced abortion in China. Fertility literacy teaches and supports breast feeding, healthy child spacing, and proper nutrition and care during pregnancy. Finally, fertility literacy provides a stepping stone to gender equity, reordering a value system that often places the worth of a domestic animal above the well-being of a woman.

Within the framework of the Safe Passages Premise and Equation, we have assembled numerous lessons learned. Foremost is the need to put in place four components to training and program development. Institutions and individuals providing skilled birth attendance must be "inspired, educated, equipped, and evaluated."

- Inspiration: Many health-care providers in Africa are burnt out. They work for low wages in demanding situations. Like all of us, they need to be reconnected to why they went into health care in the first place. Inspiration means we include spiritual topics and have a priest or minister as part of the educational team. Different levels of maternal health-care providers, such as nurses, midwives, and physicians, are encouraged to improve their working relationships and communication skills. 
- Education: Good medical care is predicated on evidence-based best practices. Thus, health-care professionals in the United States are expected and even mandated to keep abreast of developments relevant to their practice. This is not necessarily the case in Africa. While we have been impressed with the clinical skills of health-care personnel in Africa, the reality is that many healthcare providers do not receive adequate training. We have seen in many obstetrical providers' training the absence of such basic things as the use of magnesium in preeclampsia, the use of a bag and mask for newborn resuscitation, the provision of antiretrovirals for prevention of mother to child transmission of AIDS, and using the McRobert's maneuver for reducing a shoulder dystocia.

- Equipping: We have learned and relearned how unsatisfactory it is to be unable to provide the equipment and medication to go along with newly taught intervention techniques. In our first trainings in Nigeria, we set up stations at which participants enthusiastically practiced neonatal resuscitation after learning the skill. At the end of the workshop, our three bag-and-mask units were all we had for the approximately fifty institutions that were asking for them. We have since committed to bring the necessary equipment for the skills and interventions we are teaching to avoid any repeat of the near riot that followed those first trainings. Every institution receives medications and supplies: a bag and mask, vials of magnesium, partographs, fetoscopes, newborn IV catheters, vacuum extractors, etc.

- Evaluation: Evaluating the effectiveness of training and follow up is critical, yet difficult to do. If we are to be successful in implementing a pro-life paradigm, we have to gather results. When we return to do repeat trainings, we often hear from previous participants how the lives of mothers and babies have been saved and how the training has been passed on to other institutions. Yet, to date we have not had the resources to carry out thorough evaluation of programs and measure their long-term impact. Certainly a paradox is operative: those countries with the highest maternal mortality are those least likely to have the necessary funding and public-health infrastructure to assess programmatic impact.

\section{Safe Passages: Past, Present and Future}

In our first trainings in 2003, we trained over five hundred obstetrical providers in Nigeria. At that time, programmatic support was provided by the Catholic Medical Mission Board, and, in addition to emergency obstetrical care, a prevention-of-mother-to-child-transmission (PMTCT) component was introduced. Over the course of the next six years, we continued to focus on Nigeria and expanded the curriculum to include neonatal resuscitation, antiretroviral therapy for HIV-positive pregnant 
women and root-cause analysis of maternal mortality. We also incorporated the Safe Passages model into an initiative to improve the level of post-graduate family medicine training. The program, known as "AFMED: African Family Medicine Education \& Development," was successfully piloted in Jos, Nigeria. Unfortunately, political violence in Jos beginning in 2008 made it impossible for the project to continue. Until that time, we continued to partner with the Catholic Health Secretariat of Nigeria which is responsible for nearly three hundred Catholic hospitals and health centers around the country. In many of these institutions, physicians, midwives, and administrators have been trained in the Safe Passages model.

Operationally such programs ranged from $\$ 40,000$ to $\$ 60,000$ dollars per year. This allowed for training and for supplying institutions with essential medications and equipment such as magnesium sulfate, nevirapine, vacuum extractors, neonatal bag-and-mask resuscitation units, intravenous catheters, etc. Finally, we learned that pregnant women often could not afford the costs of antepartum and labor and delivery care. A subsidiary of Maternal Life International, "Aiding Infants and Mothers" (AIM), headquartered in Huntington, New York, began sponsoring care for women and babies. Through AIM, all women regardless of their income were able to receive full obstetrical and newborn care, as well as vaccines for their infants up to six months of age at Our Lady of the Apostles Hospital in Jos.

In 2009, we began training and program development in Sierra Leone, which at that time had the highest maternal mortality rate in the world. We have also focused on raising awareness of the Safe Passages model and working to develop a distance-learning mechanism for wider distribution in Africa.

As for the future of Safe Passages, we are committed to ensuring that the Safe Passage premise become a Safe Passage promise-a promise to future mothers and babies in Africa that they will experience in their lifetime a level of obstetrical care that allows them to have a pregnancy and birth free of death, free of injury, and free of the HIV virus.

Towards this commitment, we are working with the West African Fistula Foundation (WAFF) and the National Center for Health Care Informatics to build a center for training and excellence near Bo, Sierra Leone. The institution, Charity Hospital of West Africa, will provide comprehensive obstetrical care, fistula repair (presently being done by WAFF at the Bo government hospital), and on-site and distance learning for obstetrical providers throughout West Africa in collaboration with health experts in the United States and elsewhere. In addition, we are incorporating the Safe Passages training curriculum into a multi-media format for easy access to other African health-care institutions. Our goal is that Safe Passages will be a model health-care development program: one which is person-centered, evidence-based, and life-affirming. ${ }^{9}$ 
Allow us to end with a quick story. Dr. George Mulcaire-Jones's fourth child, John, spent a recent college semester in Rwanda and Uganda as an exchange student, assisting with a program called "Food for the Hungry." George asked John what was the most valuable insight he gained. According to John, in Rwanda he had a professor who had lived through the genocide and now taught conflict resolution. The professor described all of the well-meaning Europeans and Americans who had come to Rwanda in the aftermath of the genocide. They came with their laptops and notebooks, dutifully recording how many people had died, how many people had AIDS, what percentage of children were malnourished. They spoke enthusiastically and optimistically about how their program will provide this and do that. As they walked away, the professor would whisper under his breath "Just love one person."

\section{Notes}

${ }^{1}$ Margaret C. Hogan et al., "Maternal Mortality for 181 Countries, 1980-2008: A Systematic Analysis of Progress Towards Millennium Development Goal." Lancet 375 (2010): 1609-1623.

${ }^{2}$ Deborah Maine, “The Safe Motherhood Initiative," http://www.globalhealth. org/reports/report.php3?id= 311 .

${ }^{3}$ Millenium development goal number 5 : to reduce maternal mortality by $75 \%$ between 1990 and 2015. See n. 19 of United Nations, 55th session, resolution A/55/L.2, "United Nations Millenium Declaration," adopted September 18, 2000, http://www.un.org/millennium/declaration/ares552e.pdf.

${ }^{4}$ Khalid S. Khan et al., "WHO Analysis of Causes of Maternal Deaths: A Systematic Review," Lancet 367(2006): 1066-1074.

${ }^{5}$ G. Williams, "Misoprostol and Medical Abortion in Africa" (2009), http:// www.ipas.org/Publications/asset_upload_file683_4512.pdf.

${ }^{6}$ Donna Harrison, M.D, president, American Association of Pro-Life Obstetricians and Gynecologists, letter to the Office of the United Nations High Commission on Human Rights, November 27, 2009.

${ }^{7}$ M. Koblinsky et al., "Issues in Programming for Safe Motherhood" (Arlington VA: John Snow Inc., September 200o), http://pdf.usaid.gov/pdf_docs/PNACK 513.pdf.

${ }^{8}$ Pope John Paul II, Evangelium vitae, The Gospel of Life (1995), n. 96, http://www.vatican.va/holy_father/john_paul_ii/encyclicals/documents/hf_ jp-ii_enc_25031995_evangelium-vitae_en.html.

${ }^{9}$ If you would like to support Maternal Life International or learn more about our work, please contact us at mlicares@yahoo.com, through our website at http://www.mlionline.org, or at 326A South Jackson Street, Butte, Montana, 59701. Donations are tax-deductible and used to support MLI's life-affirming programs in Africa. 